\title{
A poesia intimista-militante guineense: elos entre a literatura e o engajamento político
}

\author{
The intimate-militant Guinean poetry: \\ links between literature and political engagement \\ Luís CARLOS AlVES DE MELO1 \\ ${ }^{1}$ Universidade do Estado do Rio de Janeiro (UERJ), Rio de Janeiro, RJ, Brasil
}

\begin{abstract}
Resumo: O presente artigo tem como objetivo central promover uma reflexão sobre a poesia engajada produzida na Guiné-Bissau desde os movimentos de libertação nacional até os dias atuais, desaguando no que conhecemos como literatura intimista-militante, como meio hábil para se demonstrar os elos de aproximação entre literatura e política. A literatura guineense é, sem sombra de dúvidas, exemplo de como esses dois elementos são parte de um mesmo contexto e de como podemos estar diante de obras poéticas que se transfiguram em verdadeiros manifestos políticos, assim como discursos políticos que podem ser vertidos em peças poéticas de grande valor estético.
\end{abstract}

Palavras-chave: literatura guineense; poesia intimista; engajamento; literatura política.

\begin{abstract}
This article has as main objective to promote a reflection on the engaged poetry produced in Guinea Bissau since the national liberation movements to present day, in what we know as intimate-militant literature as a way to demonstrate the links between literary and political approaches. Guinean literature's, without doubt, an example of how these two elements are part of the same context, and how we can be in touch with poetic works that transform into real political manifests, as well as political speeches that can be understood as poetic pieces of great aesthetic value.
\end{abstract}

Keywords: Guinean literature; intimate poetry; engagement; political literature.

\section{Primeiros traçados: elos entre literatura e política}

A literatura, embora não seja essa sua principal função, transformou-se com o tempo na expressão escrita e registro histórico da política, no qual uma seria o veículo pelo qual a outra poderia ser disseminada no seio das sociedades. Acerca disso, Soares (2001), no ensaio Literatura e
Política: três abordagens, registra que "as relações entre literatura e política são de forma geral entrevistas numa única direção, da política para a literatura (...) o discurso político dirige o artístico e procura-se encontrar nas obras a mensagem respectiva" (SOARES, 2001, p. 102). Nessa perspectiva, política e literatura são paralelas com ponto de interseção comuns. (SILVA; MELO, 2016, p. 393). 
O elo de união entre literatura e política é o canal pelo qual vozes silenciadas podem se tornar visíveis e sair das sombras da subalternidade. Conforme se pode observar, ao longo dos anos, a partir das produções literárias africanas, o discurso torna-se um mecanismo de libertação da opressão; é um tomar de consciência, uma espécie de epifania, tal como descrita por Henrique Dussell (1977, p. 22), ou seja, "o começo da libertação real".

Esse é um papel que a literatura guineense parece desempenhar de forma bastante natural, sobretudo do ponto de vista de sua formação. Obras como as de Odete Semedo mergulham num resgatedas memórias dos conflitos vividos no país, dentre eles os movimentos em prol da independência nacional, algo que trouxe muita instabilidade política e um deslocamento das identidades do povo local. Em outros momentos é possível apreciar o tom engajado da literatura guineense como meio de denunciação dos desmandos experimentados no país colocando, em muitos casos,a própria identidade dos(as) poetas em evidência ao se relatar a literariamente a história local.

Trata-se, portanto, de uma literatura que, dentre outros temas, navega nas águas turvas das narrativas memorialísticas dos conflitos mais recentes do país, as instabilidades políticas, a corrupção, a opressão, etc. Além disso, essas obras possuem um vínculo particular: orbitam na relação temática entre conflitos, identidades e a literatura.

Os conflitos descritos literariamente na Guiné-Bissau são significantes para entendermos a dinâmica de produção de uma literatura engajada militante e de resistência, assim como para evidenciar uma obra que busca recontar a história das guerras, golpes e abalos nacionais e para negociar identidades. O conflito é a base para a contestação das identidades e através dele surge a poesia engajada onde há uma transfiguração das subjetividades do poeta para a escrita. Ao se revelar como fonte histórica, a poesia funciona como um registro das identidades, numa relação de alteridade entre escritor e leitor e o espaço onde ela está sendo produzida. Desse modo, a literatura assume um papel utilitário e com funções diversas.

Sobre isso, Campato Jr., ao citar Osvaldo Silvestre, aponta que este autor classifica a literatura como tendo duas funções: uma formal e outra moral. A primeira função é a suscitar o prazer estético, adotando um caráter autônomo e valorativo. No que diz respeito à função moral, a literatura assume um papel de utilidade, ou seja, ela é utilizada pelo autor para um determinado fim, seja ele didático, moralista, político, cultural, social, etc." (SILVESTRE, 1995 apud CAMPATO Jr., 2012, p. 31).

Ao assumir essa função moral ou utilitária, a literatura da Guiné-Bissau revela um engajamento que busca ao fim exortar todos os guineenses, fazendo uso de uma identidade nacional coletiva, à resistência frente aos conflitos que têm atingido o país e causado tanta dor. Como bem pontou Campato Jr. (2012, p. 292), na literatura guineense há um predomínio considerável de temáticas relacionadas à questão militante e lírico amorosa, destacando-se nos últimos anos produções mais intimistas. No que diz respeito à literatura de caráter militante encontramos produções que revelam um "convite à revolução, exaltação patriótica, celebração dos heróis nacionais, denúncia das mazelas sociais, esperança 
num futuro melhor, alertas contra a ameaça neocolonialista, entre outros (CAMPATO Jr., 2012, p. 292).

\section{A poesia guineense de caráter revolucionário}

Infância

Eu corria através dos bosques e das florestas E, como o ruído vibrante de um bosque desvendado, Eu via belos pássaros voando pelos campos E parecia ser levado por seus cantos.

(Trecho de poema Infância (1963), de ANTÔNIO BATICÃ FERREIRA)

Cronologicamente falando, seguindo uma divisão baseada tanto na literatura especializada quanto em entrevistas, o período que compreende o interstício de 1945 até aproximadamente metade de 1970 da literatura guineense é denominado como Fase dapoesia de combate ou poesia revolucionária, conforme descrito por Embaló (2004) e Costa (2012). No período revolucionário surge a primeira obra em prosa de um nativo guineense chamado James Pinto Bull, autor do conto "Amor e trabalho", publicado no Boletim cultural da Guiné Portuguesa em 1952 (COUTO, EMBALÓ, 2010). Essa obra é considerada pelos literatos da Guiné-Bissau como marco inicial da literatura genuinamente guineense.

Por seu turno, na poesia, como bem lembrou o professor João Adalberto Campato Jr. (2012), o primeiro a se lançar na literatura foi o guineense Carlos Semedo com sua obra Poemas, em 1963. Para o autor, Carlos Semedo possui uma importância fundamental para o estudo da poesia guineense, pensamento esse que, ao que parece, encontra concordância na análise feita por Augel (1998). Segundo a autora, a obra de Carlos Semedo agrega "poemas que espelham seu subjetivismo, projetam estados da alma e patenteiam, na sua incipiência e apesar de tudo, uma verdadeira veia lírica" (AUGEL, 1998 apud CAMPATO Jr., 2012, p. 38).

Apreciemos, pois, uma de suas composições, o poema Monólogo' ${ }^{1}$ (1962):
Nesta solidão
d'um bar vazio
repleto de meses
desocupadas
(embora sejam
para alguém)
consigo reconhecer
a utilidade de viver
mesmo com ninguém.

Nesse período se enquadram os chamados poetas da revolução, que ganham essa alcunha por estarem inseridos ou participarem diretamente do período em que se iniciaram os movimentos revolucionários que vão desembocar na independência da Guiné-Bissau. Segundo Saliatu da Costa (2012), nessa segunda fase deparamo-nos "com uma poesia revolucionária, onde começam a aparecer os primeiros poetas guineenses, com uma linha que visava combater a dominação e incentivando, sobretudo, a luta de libertação, onde cito obrigatoriamente o Amílcar Cabral, Vasco Cabral e António Baticã Ferreira" (COSTA, 2012 s.n.). Além disso, a literatura ganha forte caracterização através de uma poesia de combate, cujo intuito não é outro senão denunciar os processos de dominação colonial, a miséria na qual o país se encontra imerso e o sofrimento do povo guineense, com vistas a iniciar as lutas para a libertação nacional, tendo o escritor Amílcar Cabral como um

\footnotetext{
O poema compõe rica produção do autor, reunida e analisada na obra "A poesia da Guiné-Bissau: história e crítica, de João Adalberto Campato Jr. (2012, p. 39).
} 
dos líderes revolucionários do período. Nesse momento suas obras assumem uma visibilidade além das fronteiras africanas, que são marcadas pela contestação do sistema colonial e pela convocação do povo à luta (EMBALÓ, 2004).

Amílcar Cabral foi o primeiro poeta guineense a liderar uma guerra de libertação. É considerado entre seus pares como um verdadeiro herói nacional, fato que pode ser notoriamente comprovado no país; o típico poeta do entre-lugar ${ }^{2}$. Segundo Couto e Embaló (2010) seus primeiros poemas foram escritos entre 1945 e 1946, em Cabo Verde, o que, por seu turno, o enquadraria, em certa medida, na transição da fase colonial da literatura guineense para a literatura combativa. Dentre suas obras mais importantes destacam-se Unidade e Luta e A arma da teoria. Além de vários artigos e obras teórico-políticas, Cabral possui ainda uma obra poética riquíssima, embora curta, com a recolha de diversos poemas escritos ao longo de sua vida pelo cabo-verdiano Oswaldo Osório.

Apreciemos um de seus poemas, intitulado Eu sou tudo e sou nada...

Eu sou tudo e sou nada...

Eu sou tudo e sou nada,

Mas busco-me incessantemente,

- Não me encontro!

Oh farrapos de nuvens, passarões

não alados,

levai-me convosco!

Já não quero esta vida,

quero ir nos espaços

para onde não sei ${ }^{3}$.

2 Refere-se ao ponto intersticial, ou seja, à fronteira entre a tradição e o contemporâneo. No caso em questão, refere-se ao embate entre a tradição colonial e a luta de libertação. Cf. BHABHA (1998).

3 FENSKE, E. K. (pesquisa, seleção e organização). Amílcar Cabral -- o poeta da liberdade. Templo Cultural Delfos. Disponível em: < http://www.elfikurten.com.br/2015/09/ amilcar-cabral.html>. Acesso em: 20 out. 2018.
Outro representante desse período é o escritor Vasco Cabral que, conforme registra Embaló (2004), se enquadra como o de maior produção poética literária da GuinéBissau, além de ter abordado uma infinidade de temas. Suas contribuições abordam temáticas que envolvem o oprimido e a luta, a miséria e a esperança, o amor e a paz, etc. Esse é um poeta que transita entre duas fases da literatura guineense, haja vista que sua obra mais famosa de poemas, $A$ luta é a minha primavera, foi publicada em 1981, enquadrando-a na fase denominada poetas da independência (EMBALÓ, 2004; COUTO, EMBALÓ, 2010, p. 70).

Os traços de uma poesia revolucionária e de combate, de viés político, podem ser vistos através de sua composição $O$ último adeus de um combatente (1955), apresentada na obra de Campato Jr. (2012, p. 50).

Naquela tarde em que eu parti e tu ficaste

sentimos, fundo os dois a mágoa da saudade

Por ver-te as lágrimas sangrarem de verdade

sofri na alma um amargor quando choraste

Ao despedir-me eu trouxe a dor que tu levaste!

Nem só o teu amor me traz felicidade

Quando parti foi por amar a Humanidade

Sim! Foi por isso que eu parti e tu ficaste!

Mas se pensares que eu não parti e a mim te deste

será dor e a tristeza de perder-me unicamente um pesadelo que tiveste.

Mas se jamais do teu amor posso esquecer-me

e se fui eu aquele a quem tu mais quiseste

que se conserve em ti a esperança em rever-me! 
O canto-poema de Vasco Cabral se insere num contexto social da representação das guerras de revolução pelos quais o país há de passar. Ao tecer as tramas do soneto, o autor não apenas apresenta um viés histórico de seu país (com manutenção da estética), mas traça os caminhos de edificação da poesia guineense. Conforme registra Campato Jr. (2012):

Diversamente de Amílcar Cabral, de Antônio Baticã Ferreira e de vários poetas incorporados nas antologias coletivas, Vasco Cabral constitui poeta vital para as letras guineenses, que seja sob o enfoque histórico, quer seja o estético. Com ele, podemos afiançar que a poesia da Guiné-Bissau principia, de forma mais resoluta e artística, a edificar os alicerces (CAMPATO JR., 2012 p. 45).

Por último, mas não menos importante, inclui-se nessa periodização o poeta guineense António Baticã Ferreira. Das suas obras mais importantes, seis poemas integram a coletânea, No reino de Caliban (1975), de Manuel Ferreira, e outro deles integra Poetas e contistas africanos (1963), de João Alves das Neves. (COUTO, EMBALÓ, 2010 p. 70). Embora esteja inserido num contexto de revolução, o autor não se rende unicamente a essa temática, pelo contrário, os temas mais comuns de sua poesia são amor, suavidade e a beleza da natureza.

\section{Os poetas independentistas: política e revolução}

Sob estes ventos soalheiros da revolução que as quedas não sejam definitivas

e que os desfalecimentos sejam vencidos pela certeza da vitória que amanhecerá nas frescuras das madrugadas ${ }^{4}$.

(Momentos primeiros da Construção [1978], de JOSÉ CARLOS SCHWARZ)

4 Cf. CAMPATO Jr. (2012, p. 80).
Do final dos anos 1970 aos fins dos anos 1980, a literatura guineense compreende o que chamamos de Fase da poesia independentista ou dos poetas da independência, na qual estão inseridos autores que estão produzindo uma escrita exclusivamente poética, que transita desde uma poesia de combate até uma poesia mais intimista (EMBALÓ, 2004; COSTA, 2012). Não deve suscitar estranheza o fato de essa fase apresentar semelhanças com sua anterior ou com a vindoura, haja vista que a fronteira entre uma fase e outra é tênue e, na maioria das vezes, uma fase adentra a outra e vai se modificando.

Em seu Manual de Literaturas de Língua Portuguesa $^{5}$ (2016), Campato Jr. lança luz ao nosso entendimento ao registrar que, em geral, os poetas, em virtude da condição de colonização vivenciada, acabam adotando certo engajamento literário e, portanto, ao produzirem uma literatura nacional lhe dão características militantes (CAMPATO JR., 2016).

Não é demais lembrar que é pacífica, mas não unânime, entre alguns historiadores a relação íntima que existe entre a história e a literatura, de modo que a história "evidencia a força das representações do passado propostas pela literatura" (CHARTIER, 2009, p. 25). Na Guiné-Bissau há um entrelace de ambas para se reconfigurar a história do país. A história guineense é responsável pelo que lá se produz e, portanto, sua literatura é um dos maiores registros históricos dos quais o país dispõe.

\footnotetext{
Recentemente lançada, a obra apresenta uma visão inovadora ao trazer à superfície autores de rica contribuição literária, mas que não figuram no cânone literário. É obra fundamental para os estudos das literaturas em língua portuguesa, tanto para iniciantes quanto pesquisadores longevos. Cf. CAMPATO JR. (2016).
} 
Essa breve digressão é importante para entendermos o tipo de literatura que se produz em determinadas fases, em virtude do momento político, histórico e social em que se está inserido. Por meio da literatura "vozes silenciadas podem sair das sombras da subalternidade, na qual, por muitos anos, foram postas pelas vias da opressão" (SILVA, MELO, 2016, p. 393). É com tal vigor que na visão de Saliatu da Costa (2012) "ergueu-se um braçado de jovens poetas com a independência, cujos ideais faziam parte a denúncia da repressão e um apelo à construção de uma nação livre". Dentre os destaques dessa fase é consenso entre Embaló (2004) e Costa (2012) que as primeiras antologias do país foram Mantenhas para quem luta (1977) e, posteriormente, Antologia dos novos poetas / primeiros momentos da construção (1978). Ambas consagram uma poesia de reconstrução do país. Além disso, participam dessa geração de autores: Agnelo Regalla, Helder Proença, Huco Monteiro, Francisco Conduto de Pina, Tony Tcheca, Félix Siga, José Carlos Schwarz, entre outros. (EMBALÓ, 2004; COSTA, 2012).

É nesse período que surge uma poesia guineense propriamente dita, embora ainda com predominância da língua portuguesa. Temas como colonialismo, escravatura e repressão passam a fazer parte das produções da época, conduzindo a um discurso de apelo à construção nacional, liberdade e esperança. As identidades, antes submetidas às grades coloniais, se tornam questões fundamentais entre os escritores, de modo que sua evocação é uma busca pela reafirmação de uma cultura nacional. Entretanto, a identidade não é uma oposição entre o sujeito e sociedade, pelo contrário, "ela é analisada como um conflito pessoal do indivíduo, que consciente do seu defasamento cultural em relação à sociedade de origem, procura identificar-se com as suas raízes, da qual foi afastado pela assimilação colonial" (EMBALÓ, 2004, s.n.).

Como bem apontam Couto e Embaló (2010, p. 71):

A primeira fase desse período é a de Afirmação da Nacionalidade, da identidade, por ser a fase de "construção da nação". Aliás, esse é justamente o título de um congresso, realizado no país em 1986, cujas atas foram publicadas como A construção da nação em África (Bissau: INEP, 1989). $\mathrm{O}$ fato de as comunicações dedicadas à Guiné-Bissau serem mais numerosas não é apenas porque o evento se deu no país. É que, entre os cinco países representados (Angola, Cabo Verde, São Tomé e Príncipe, Moçambique e GuinéBissau), é justamente a Guiné-Bissau que tem mais problemas de identidade nacional. As únicas coisas que a unem, precariamente, são o território, o crioulo e a tradição da colonização portuguesa.

Os primeiros registros que se têm sobre essa fase dão conta que Poilão (1973) foi uma das primeiras obras lançadas, não exclusivamente por guineenses, mas com o contributo de poetas cabo-verdianos. Dos guineenses que participaram da obra citada destacam-se Pascoal D'Artagnan Aurigemma, Atanásio Miranda, António Baticã Ferreira e Tavares Moreira, dos quais Miranda e Moreira parecem não ter dado continuidade aos trabalhos, pelos menos não que se saiba, haja vista que não se encontram registros de poesia posteriores. Em 1977, como já adiantamos, teve registro a obra Mantenhas para quem luta, com contributo de 14 autores de destaque entre os intelectuais guineenses, dentre os quais encontramos Agnelo Regalla e 
Antônio Soares Lopes Jr., o Tony Tcheka. Em 1978 é publicada a primeira coletânea individual guineense, Garandesadi no tchon, por Francisco Conduto de Pina. (COUTO, EMBALÓ, 2010). A despeito do autor, Campato Jr. (2012 p. 184) afirma que "sua poesia é, indiscutivelmente, um dos modelos da melhor literatura que se tem produzido na Guiné-Bissau".

Posteriormente, em 1978, surge na Antologia dos jovens poetas uma das primeiras vozes femininas da qual se tem conhecimento na poética guineense, Mariana Marques Ribeiro. Como pudemos observar ao longo de nossas análises bibliográficas, esse fato resguarda fundamental importância para a literatura guineense. Em países como a Guiné-Bissau o patriarcalismo praticamente abafava um protagonismo feminino, exercendo, tal como afirma o professor Thomas Bonnici (1997 p. 198), “o controle e a repressão da mulher pela sociedade masculina". Na referida antologia, se dedica um espaço para obras escritas em crioulo. No ano seguinte, em 1979, veio à tona a obra Os continuadores da Revolução e a recordação do passado recente, coletânea composta por 23 autores que, conforme salientam Couto e Embaló (2010, p. 73), eram “jovens com uma grande vontade de produzir e ajudar na construção da nação".

Agnelo Regalla é poeta de grande expressão nessa fase, cuja marca é o discurso político que é inerentemente compatível com sua biografia. Embora não tenha editado nenhuma obra individual que se saiba, teve grande participação nas principais antologias que consagraram a literatura guineense (CAMPATO JR., 2012, p.121-122). Vasco Cabral, que aparece na fase anterior da literatura guineense, também pode ser visto caminhando pela fase independentista, afinal de contas a fronteira entre uma e outra é muito tênue. A obra que faz essa ponte é "A luta é a minha primavera" (1981), mas que agrega poemas datados de 1951 a 1974 (CAMPATO JR., 2012 , p. 46). Por essa particularidade, acreditamos que o poeta se enquadra nas duas fases da literatura guineense, tal como ocorre com outros poetas, dentre eles Tony Tcheka. Contudo, dado que grande parte de sua obra individual é datada no pós-1990, optamos por inserir esse autor na fase a seguir. Com o rigor, no entanto, não podemos nos furtar de registrar que Tcheka aparece primeiramente como um dos grandes nomes dos poetas da independência.

Não poderíamos terminar sem trazer a lume uma das mais emotivas composições escritas por Agnelo Regalla, uma homenagem ao líder revolucionário Amílcar Cabral, morto em 1973. O poema é lido em muitos encontros culturais guineenses, conforme registra Campato Jr. (2012, p.123). Desfrutemos, pois, de Camarada Amílcar (1974):

No chão vermelho

Do teu sangue, Camarada,

Caem como gotas de orvalho

As lágrimas sinceras de dedicação.

As flores da nossa luta

Que tu com carinho plantaste,

Estão a desabrochar

Em gargalhadas infantis

E descansa, camarada Amílcar,

Descansa que não secarão.

Serão sempre regadas

Com o nosso suor e sangue,

Serão Sempre alimentadas

Pela força a nossa vontade.

E serão camarada Amílcar,

Serão livres... livres...

Livres como as gargalhadas que saltam

Livres como o sol do nosso hino,

Livres como o vento que desfralda 
A nossa bandeira,

Livres, como a liberdade com que sonhaste.

É assim camarada, é assim...

Uns chegam ao fim,

Mas outros ficam pelo caminho

Não por desfalecimento,

Mas pelo seu valor e coragem.

E dentre todos,

Os mais felizes

Serão os que conseguirem plantar

As flores que deixaste,

No canteiro livre

Da Guiné e Cabo Verde ${ }^{6}$.

Finalmente, já na transição para a próxima fase, em meados dos anos 1990, surge a coletânea poética, a "Antologia Poética da Guiné-Bissau", em Lisboa, produzindo um tipo de poesia intimista, algo que será alvo de nossas considerações no próximo tópico.

\section{O discurso intimista-militante: resistir em rimas e versos}

\author{
Despe-me, se breve \\ arranca os meus farrapos \\ rasga a minha alma imunda e profana \\ esgazeia bem os olhos \\ dá o teu melhor veneno \\ transmutando o meu desejo num alvoroço \\ afaga a minha pele \\ melhor que o vento impertinente \\ ensaboa-me as nádegas \\ aconchega-se nas minhas ancas codórias \\ aceita que sou mulher \\ (Poema Prazer ${ }^{7}$ [2008], de \\ SALIATU DA COSTA)
}

A partir da década de 1990 (até os dias atuais), emerge nos veios da história guineense a fase da literatura guineense chamada de poesia intimista. Nessa fase estão alocados os grandes nomes da literatura guineense que estiveram presentes

\footnotetext{
6 Cf. CAMPATO Jr. (2012 p. 123-124)

Retirado da obra Bendita Loucura (2008). Cf. Referências.
}

nas outras fases e que estão surgindo pouco a pouco. Segundo Embaló (2004), essa é uma fase marcada pelo desencantamento dos sonhos pós-independência imediata, algo que, em larga medida, fez com que houvesse uma transformação da poesia para algo mais intimista, introspectivo. Nessa fase, as temáticas referentes à nação, às identidades, ao indivíduo, entre outros, passam a inspirar novas produções. Dentre os nomes que se encontram nessa fase destacam-se: Helder Proença, Tony Tcheka, Félix Sigá, Carlos Vieira, Odete Semedo, Saliatu da Costa entre outros (EMBALÓ, 2004; COSTA, 2012).

A literatura intimista adota uma escrita mais introspectiva, na qual os poemas, contos e poesias assumem um caráter mais íntimo, expondo os sentimentos, emoções, frustrações, desejos dos sujeitos envolvidos. Deixar transparecer os anseios mais profundos da alma, expressar de forma confidencial o que o peito guarda, essas seriam as melhores definições para o conceito intimista que se faz presente. Em termos simples, a poesia intimista reflete a expressão individual do artista, apresentando-se como uma poesia confessional. Uma definição teórica dessa literatura vem dos trabalhos do professor Russell Hamilton. Para ele, "(...) o intimismo é uma metáfora pela coletividade - serve como medianeira entre a componente instrumental e o elemento sentimental inerente à consciencialização do colonizado em busca da sua realização dentro dos limites da ordem política" (HAMILTON, 1984 p. 249).

$\mathrm{Na}$ literatura guineense, esse intimismo aparece como uma marca central dos discursos poéticos dessa fase, adotando em determinados casos, quando não em sua maioria, um caráter intimista-militante. 
Rigorosamente falando, não há problema de lógica na denominação poesia intimistamilitante, já que nos dias que correm a crítica tem se valido de denominações muito semelhantes, como por exemplo: lirismo social, lirismo de participação ou mesmo lirismo interventivo. Todos esses rótulos se referem ao fato de que as poéticas militantes, quase sempre, refletem, além de um direcionamento para o exterior, os anseios e mágoas da alma do artista que, na maioria das vezes, impossibilitado de expor sua opinião, expressa-a em suas produções. Como não poderia deixa de ser, nesse gênero de literatura é necessário o equilíbrio, pois o excesso de engajamento político pode ocasionar uma fratura na composição, fazendo com que a poesia perca sua beleza.

No ano de 1992, surge no cerne da literatura guineense a obra $\mathrm{O}$ eco do pranto: a criança na moderna poesia guineense, cuja organização ficou a cargo de Antônio Soares Lopes Jr., o Tony Tcheka. Conforme aponta Campato Jr. (2012), o autor é reconhecido entre os seus pares como patrono da literatura guineense: "Tratase de poeta cuja produção no terreno da literatura, diferentemente do que se passa com boa parte dos literatos do país, é de notável constância" (CAMPATO JR., 2012, p. 85). É dele, ao lado de Antônio Baticã e Helder Proença, o verbete "Literatura da Guiné-Bissau", no Dicionário temático da lusofonia. Em 1996, o poeta lançou Noites de insônia na terra adormecida, através do Instituto Nacional de Pesquisa da GuinéBissau (INEP). A segunda obra veio em 2008, com o título Guiné - Sabura que dói, prefaciada por Filomena Embaló (ibidem, p. 86). A terceira obra fundamental desse autor foi lançada recentemente, em 2015, sob o título Desesperança no chão de medo e dor, com prefácio de Moema P. Augel e contribuições analíticas de Odete Semedo, Robson Dutra e João Adalberto Campato Jr. (CAMPATO JR., 2015, p.325). Cabe registrar que Tcheka também lançou uma obra referente ao campo do jornalismo, no qual ele possui formação, intitulada Os media na Guiné-Bissau.

Vejamos a última estrofe de Mulher da Guiné, poema que estampa as páginas de Guiné - Sabura que dói (2008), e que exalta a mulher guineense em toda sua representatividade. A composição foi reproduzida e analisada por Campato Jr. (2016, p. 334).
Mulher da Guiné
corpo veludo sossego
musicado em sons de flauta
duas pequenas luas
explodindo na cara canseira
asseda os tormentos
caminha fêmea como a tua Guiné a novos partos de sabura ${ }^{8}$.

Helder Proença é figura que goza de grande prestígio tanto dentro quanto fora de seu país. Militante das guerrilhas de libertação no interior do país, ocupou cargos no PAIGC e foi professor do ensino secundário (CAMPATO JR., 2012, p. 159). Sua vocação para a política suplantou sua veia poética, tanto que, conforme noticiam os pesquisadores da área, desde 1992 não se verificam produções suas no campo da literatura guineense. Proença, como já dissemos anteriormente, integrou com Tony Tcheka a antologia Mantenhas para quem luta! (1977), além de Momentos primeiros da construção (1978), Antologia poética da Guiné-Bissau (1990) e, finalmente, O Eco do Pranto (1992). Integra essa fase

\footnotetext{
8 Segundo Campato Jr. (2012 p. 97), o termo "significa felicidade, sabor, gostosura, maravilha".
} 
por apresentar uma poesia militante por excelência, além de transitar pela fase dos poetas independentistas (CAMPATO JR., 2012, p. 160).

Felix Sigá, cujo verdadeiro nome é Xilef Agis, figura ao lado de Tony Tcheka e Odete Semedo como um dos integrantes do trio tutelar da literatura da Guiné-Bissau. Figura, ainda, junto com outros autores já citados aqui nas antologias: Antologia poética da Guiné-Bissau (1990), Eco do Pranto (1992) e Portuguesia (2009). Em 1996, publicou uma obra individual chamada Arqueólogo da calçada que recebeu prefácio de Teresa Montenegro (CAMPATO JR., 2012, p. 146). Conforme registra Augel (2007), o autor é "entre os poetas guineenses, aquele cujos textos mais ressaltam a amargura, o desamparo, frutos de conflitos identitários não resolvidos, levando-o a não acreditar em nada (...)" (p. 245). Além desses temas, a reflexão sobre o mundo é outra temática de grande repercussão em sua poesia. Infelizmente, o autor veio a falecer no ano de 2015, deixando órfã a literatura guineense.

Odete Semedo é uma das principais, mas não a única, escritora guineense responsável por obra de grande importância na literatura do país, cujo trabalho pioneiro se desenvolve no campo da oratura, sobre grupos típicos da sociedade guineense, as chamadas mandjuandadis ${ }^{9}$ (AUGEL, 2007 p. 102). Sua obra está dividida entre poesia e prosa de ficção, dentre as quais podemos apontar duas delas, quais sejam: Entre $O$ ser e o amar (1996) e No fundo do canto (2003). Segundo Campato Jr. (2012), foi

9 Segundo Odete Semedo (2010, p. 135), a Mandjuandadi é uma associação ou um grupo de pessoas da mesma idade ou, ainda, da mesma geração, que se organizam para confraternizações e apoio mútuo em ocasiões ou circunstâncias diversas. Para mais informações, conferir a densa tese de doutorado de Odete Semedo. Disponível em: <http://www.biblioteca.pucminas.br/teses/Letras SemedoMO_1.pdf $>$. Acesso em 10/08/2018. a primeira delas que garantiu à autora o título de primeira mulher a lançar uma obra individual, o que lhe confere "valor histórico e relevância estética" (p.196). Dentre os temas de destaque de sua poesia, a questão do pertencimento cultural é a que mais se registra, fortalecendo, em consequência, a problemática da identidade cultural. Além disso, podemos ver em suas obras traços confessionais típicos dessa fase intimista da poesia guineense.

Vejamos o poema $E u^{10}$ (1996):

Na poesia liberto-me

Sou poeta

Sou livre

Enquanto poeta

A natureza leva-me embalada

Apodera-se do meu ser

E da minha alma

Enquanto poeta

Sou apenas eu.

Na fase intimista nasce uma geração que se elege com a alcunha de pindjiguiti, na qual encontramos a poetisa contemporânea chamada Saliatu da Costa. Trata-se de autora, até então, pouco conhecida do cânone literário, mas cuja capacidade de atingir de forma sensível a todos os públicos é latente. Ao longo de sua caminhada pelos campos literários, escreveu alguns artigos e duas obras poéticas, todos de grande importância para a história da literatura africana de língua portuguesa, levando-se, sobretudo, em consideração sua contribuição para a difusão da cultura negra. Dentre seus feitos, podemos destacar as duas obras que marcam momentos importantes dentro de sua poesia. São elas: Bendita Loucura (2008) e Entre a Roseira e a Pólvora, o Capim (2011) (CAMPATO JR., 2012, p. 257).

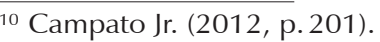


Atualmente, muitas têm sido as contribuições de pesquisadores que têm dedicado boa parte de sua caminhada acadêmica para desenvolver trabalhos sobre a literatura, cultura, política da Guiné-Bissau. Essas obras compõem rico acervo de estudo para essa literatura e, não poderíamos, por amor ao rigor, deixar de considerar a contribuição desses autores. As obras de maior revelo, segundo nosso entendimento, fundamentais para um estudo dessa literatura são: A literatura na Guiné-Bissau (1997), de Aldónio Gomes e Fernanda Cavacas, O desafio do escombro: a literatura guineense e a narração da nação (2007), de Moema Parente Augel, 2005, A poesia da Guiné-Bissau: história e crítica (2012) e, recentemente, Manual de Literaturas de Língua Portuguesa: Portugal, Brasil, África Lusófona e Timor-Leste (2015), ambas da autoria do professor João Adalberto Campato Junior.

\section{Pinceladas finais: o engajamento político-literário guineense}

As dominações coloniais representaram grande problema na elaboração das identidades dos países vítimas do processo de colonização tais como Angola, Cabo Verde, Moçambique, São Tomé e Príncipe, Timor-Leste e na Guiné-Bissau. Essa questão se tornou proeminente porque tais dominações atropelaram as culturas e costumes locais, sufocando as formações identitárias existentes, e criaram uma conotação negativa e estereotipada sobre essas culturas, ao tentar incorporar os costumes europeus.

Como resultado, o que se viu, na literatura guineense, por exemplo, é que, ao longo dos anos, houve uma gradativa mudança temática na produção poética que tem seu início ainda no período colonial e que chega até meados de 1945, e seu desembocar em uma literatura que agregou traços confessionais, uma poesia intimista, em meados dos anos 1990.

É no bojo dessa expressão literária que surge na Guiné-Bissau de forma mais intensa, embora já se possam observar traços em outras épocas, uma poesia engajada militante. A partir dessa renovação, mais do que falar do cotidiano, a literatura africana em língua portuguesa e a guineense, em particular, ganham ares de contestação, com forte presença de questões ligadas a cultura e origens identitárias. Um dos pontos que, ao que nos parece, ganhou maior destaque, foi o engajamento literário dos poetas, assumindo uma postura de defesa de determinados pontos de vista ou critica moral e social, questionando as ordens de poder vigentes e reivindicando a nação. Segundo Abdala Jr., esses poetas engajados lograram êxito ao produzirem sua literatura dento do "campo intelectual descolonizado", mas a questão principal é que eles não produziram para públicos colonizados, mas para o que eles entendiam ser o seu povo. Dessa consciência, surgiram literaturas nacionais africanas em língua portuguesa, embora ainda coloniais, "ao contrário do que ocorreu em outros países africanos" (ABDALA JR., 2007, p. 101).

Em países onde a expressão literáriocultural possui uma proeminência forte entre os indivíduos, seja por meio de uma literatura oral ou escrita, o recurso do militante assume um papel de grande importância, uma vez que traz à tona as principais reivindicações de um povo. Mas afinal, o que de fato significa esse caráter engajado e militante na literatura? Se estamos aptos a escolher um termo que melhor traduza a essência de engajamento 
literário na poesia, esse seria "autonomia". Expliquemos.

Quando pensamos no caráter de uma poesia engajada, uma das primeiras coisas que nos vem à mente é a necessidade de um posicionamento demarcado pelo poeta, livre e autônomo. Isso quer dizer que há sempre uma necessidade de se escolher uma posição, um lugar de fala, uma ideologia, dentre muitas outras, quase sempre contraditórias e contrárias. Tendo feito sua escolha e estando certo delas, o poeta passa a defender o seu ponto de vista baseado nas escolhas que fez livremente, sem pressões. Nesse momento podemos dizer que o que está sempre produzido é uma literatura engajada. Esse tipo de literatura é, antes de mais nada, uma produção ideológica e de lados definidos.

Além disso, ela é autônoma porque, ao tornar-se livre de modismos, passa a contestar uma ordem vigente, assumindo uma roupagem predominantemente militante. Embora assuma uma posição que pode ser entendida em primeiro momento como uma produção tendenciosa, não é esse o propósito da literatura militante, embora a distância entre o "tendencionismo" e engajamento seja limítrofe. Para Oliveira (2001, p. 57), "o texto engajado pode atingir alturas se conseguir manter-se plurissignificativo, se tiver aquela ambiguidade que enriquece o sentido. Mas se dele desaparecer a liberdade, serão apenas teses ilustradas (...)".

Se observamos o contexto histórico da Guiné-Bissau, assim como o dos demais países de língua portuguesa, veremos o porquê de tantas produções ressaltarem o caráter político e social. Não se trata apenas de um rememorar para recontar, mas recorrer ao passado para estabelecer os mecanismos de resistência em prol de todos. É uma luta diária contra uma história de opressão e silenciamento que fez ruir e continua desestabilizando as estruturas sociais da nação. O mergulhar poético numa literatura engajada exige uma reflexão e o embate entre os diferentes saberes. "O gosto estético se associa à perspectiva política, a metodologia analítica à avaliação histórica, a subjetividade à funcionalidade, a clareza à expressividade" (PEDROSA, 1994, p. 27). Esse talvez seja um dos grandes problemas que uma literatura africana sofreria em virtude de seu histórico de opressão. Segundo Campato Jr, o caráter engajado da literatura guarda relação direta com as dominações coloniais, fazendo nascer um espírito de resistência e denúncia por parte dos autores africanos.

Em virtude da opressão colonialista que determinados países africanos sofreram do imperialismo europeu, natural concluir que boa parte da literatura dessas nações apresentará característica militante pronunciada. Nesse aspecto, um problema se coloca: um dos resultados da arte concebida à luz da função moral ou utilitária (literatura engajada) é o eventual e exagerado feitio panfletário de que algumas obras acabam se revestindo, relegando a segundo ou terceiro planos o suposto aspecto artístico da literatura. Em tais ocasiões, a possível obra de arte cederia lugar ao unívoco discurso político, social, religioso etc., que concebem a linguagem dos textos transparentemente, sem problematizá-la (CAMPATO JR., 2016, p. 287).

Consideremos como literatura engajada toda a produção que tem como princípio fundamental a defesa de uma determinada causa, seja ela histórica, política, social, ideológica, econômica e etc. Conforme vimos em Abdala Jr. (2007, p.98), “a literatura, alimenta-se dos discursos da 
política, da sociologia, da economia, e não, diretamente, dos fenômenos concretos. É das relações materiais entre os homens que aparecem esses discursos que serão mediatizados pela ideologia para, daí, serem objetos de apreensão literária". O resultado dessa conformação (entre a literatura e os discursos), em determinados momentos, não é tão perceptível ao leitor, principalmente se este não estiver a par do histórico de conflitos pelos quais passou um determinado país onde essa literatura é produzida. Muitas vezes, o recado poético está infiltrado nas entrelinhas como uma mensagem enigmática a ser desvendada pelo leitor mais atento.

Um ponto que precisa ser devidamente esclarecido aqui diz respeito ao alcance dessa poesia em relação a seu alvo. Pelo que já foi exposto, poderíamos pensar que o poeta engajado seria aquele que usa sua literatura para produzir um discurso de ataque contra os "donos do poder", nisso incorreríamos em grave erro. Isso porque quando um poeta apenas se utiliza do espaço literário para atacar a política, sem ao menos refletir sobre como as situações caóticas puderam alcançar o nível que alcançaram, ele corre o risco de ver seu discurso atingir um fim outro, diferente do esperado, isto é, ele pode acabar no tabuleiro do jogo de poder e jogar esse mesmo jogo à maneira dos seus acusadores. O poeta engajado não é aquele que usa sua literatura para criticar sem refletir, mas sim aquele que, tendo refletido sobre o contexto de sua nação, tem mecanismos e elementos que legitimem suas reivindicações e sua denúncia. Não se trata utilizar a poética para atingir um determinado fim a todo custo, mas um processo contínuo de produção que não só pense apenas num fim em si, mas em todos os elementos que estão por trás desse fim.

Importa à literatura engajada não o fato de olhar para fora de seu país, mas consciência crítica do sentido ideológico do trabalho artístico realizado. Essa consciência deve efetivar-se não apenas em relação a fatores referenciais, mas sobretudo em relação à dinâmica da série literária nacional. Nessa situação político-cultural que aproxima as literaturas de ênfase social em português, o dominante dialético aponta para a nacionalidade, quer consideremos essa polaridade interno/externo diante do nosso sistema literário ou as interações desse último com as dos outros sistemas ou microssistemas. O jogo artístico, a ser articulado na dialética região/país, ou país/países de língua portuguesa, ou ainda países de língua portuguesa/ literaturas de outros sistemas linguísticos, deverá renovar patterns próprios da literatura nacional. (ABDALA JR., 2007, p. 50).

É por essas e outras questões que a grande tática dos autores de uma literatura mais engajada é concentrar seus discursos em prol das desigualdades, da violência sistemática na nação, nos conflitos sequentes que se propagam no Estado, da resistência frente à repressão, da luta em prol de todos, etc. O literato engajado não é um indivíduo neutro, e esse talvez seja o elemento principal para se entender como se dá sua poesia. Para se pensar essa questão em relação à Guiné-Bissau, basta que observemos o texto ficcional de Filinto de Barros, cuja retórica tem como alvo a questão nacional e a luta pela independência do país.

Segundo Augel (2007) as marcas de sua poesia, observadas por meio do uso de iniciais maiúsculas, tais como "Luta, Combatente, Comandante, Partido" dão 
ao texto um valor mítico e denotam um engajamento por parte do autor. Ainda, de acordo com a autora, "o romance KikiaMatcho desempenha sem dúvida um papel importante para a literatura e para a construção da ideia de nação e de nacionalidades guineenses" (AUGEL, 2007, p. 303). Logo, o que se vê é que a literatura engajada é um mecanismo de luta e resistência, algo que para Campato (2012, p. 33) permanece latente até os dias atuais, "quando a literatura tem de estar às voltas com a frustração dos sonhos não realizados pela independência política, com a ameaça constante do neocolonialismo e da globalização e com a autocolonização".

Esse medo que circunda constantemente o espaço da nação acaba por fortalecer a poesia combativa militante. $\mathrm{O}$ autor assume um papel de cidadania, um papel social em busca de isonomia e melhorias para os seus pares e tem, em sua ação militante, o combustível para compor sua obra. Os poetas ou as poetas militantes têm em mente uma causa pelo qual desejam lutar e por isso se utilizam de sua literatura para deixar transparecer seus desejos. Desse modo, a literatura passa de produto cultural a elemento de luta, resistência e transformação de uma sociedade. A postura militante questiona, por exemplo, as relações de poder e as opressões sofridas pelos povos africanos, seja no período de colonização, seja durante os abalos sofridos pela nação ao longo dos anos. Nesse sentido, procedese verdadeira denúncia sobre os abusos enfrentados pelas diferentes esferas sociais do Estado, em momentos adequandoaao lado estético da poesia, em outros deixando-o de lado.

Para Abdala Jr., há na produção desses autores um processo de correspondência entre a literatura e os discursos sociais, o que emerge de novas formas de articulação. "E, dessa maneira, por sobre padrões de conduta convencionais, rearticulase a série literária de conformidade com configurações ideológicas que aspiram à hegemonia social". (ABDALA Jr., 2007, p.95). Saliatu da Costa (2012), quando questionada sobre o caso da literatura militante, argumenta que é difícil deixar de lado a tristeza e a revolta com o que se passa na política, e isso, portanto, acaba se refletindo diretamente na forma como o autor constrói a sua poesia. Tendo passado por tantos momentos de tamanha incerteza no país, o escritor guineense percebe que não há como fugir dessa árdua tarefa, tomada quase como um destino. E questiona: “(...) por que não inverter e transformar um discurso político numa poesia?".

Tendo isso em mente, ao formular uma poética que busca reafirmar suas identidades individuais, o sujeito poético reproduz em sua poesia traços da coletividade e, porque não dizer, da nação. SegundoAppiah "o simples gesto de escrever para e sobre si mesmo (...) tem uma profunda significação política". (APPIAH, 1993 apud AUGEL, 2007 p. 265). Mais do que isso, a escrita poética guineense é o reflexo de um ambiente conflituoso onde as identidades estão em polvorosa, tentando se adequar a novos espaços sociais. Ao se fragmentarem em inúmeras formulações identitárias, os poetas descritos querem tirar as vendas da opressão dos olhos do povo da GuinéBissau, fazendo-os enxergar as injustiças que cercam a pátria amada.

Nesse sentido, as obras engajadas dos poetas guineenses buscam representar como o conflito impacta nas identidades, ao mesmo tempo em que clama aos filhos 
da terra para lutar. Essas poesias, cada uma a sua maneira, demonstram como o escritor, ao assumir um papel social e político, está intimamente se identificado com seu povo, exercendo ao mesmo tempo o papel de "porta-voz e intérprete" (AUGEL, 2007).

Logo, é essencial que a história do povo guineense seja verificada e apresentada a todas as camadas sociais. Ao resgatar autores que pela própria história e militância, mesmo inconsciente, dão voz aos silenciados e apresentam ao mundo a verdade de um povo cujos desafios e lutas foram e são fardos pesados. É pela literatura que os autores podem expressarse e dar vazão àquilo que está preso no âmago de seu ser; e, nas entrelinhas, retirar as mordaças históricas que continuam a existir, denunciando os desmandos, o abandono, a ditadura, o cerceamento à liberdade e os esquecimentos.

\section{Referências}

ABDALA JR., Benjamin. Literatura, História e Política: Literaturas de língua portuguesa no século XX. 2. ed. Cotia, SP: Ateliê Editorial, 2007.

AMADO, Leopoldo. Guineidade\&Africanidade: estudos, crônicas, ensaios e outros textos. Lisboa: Edições Vieira da Silva, 2013.

AMORIM, Cláudia; PALADINO, Mariana. Cultura e literatura africana e indígena. Curitiba: IESDE/ Brasil, 2010.

ANDRADE, Mário P. A guerra do povo na GuinéBissau. 2. ed. Lisboa: Sá da Costa Editora, 1975. (Cadernos Livres).

APPIAH, Kwame Anthony. Na casa de meu pai: a África na filosofia da cultura. Rio de Janeiro: Contraponto, 1997.

AUGEL, Moema P. A nova literatura da GuinéBissau. Bissau: INEP, 1998.

O desafio do escombro: nação, identidade e pós-colonialismo na literatura da Guiné-Bissau. Rio de Janeiro: Garamond, 2007.

BARROS, Miguel de. Percepções sobre a intimidade e o corpo feminino na literatura poética da Guiné-Bissau. In: SANTOS, J. H. F.; RISO, R. (Org.). Afro-rizomas na diáspora negra: as literaturas africanas na encruzilhada brasileira. Rio de Janeiro: Kitabu, 2013. p. 131-141.

BAUMAN, Zygmunt. Identidade. Rio de Janeiro: Jorge Zahar, 2005.

BHABHA, Homi K. O local da cultura. Belo Horizonte: Editora da UFMG, 1998.

BENJAMIN, Walter. O narrador: considerações sobre a obra de Nikolai Leskov. Magia e técnica, arte e política: ensaios sobre literatura e história da cultura. São Paulo: Brasiliense, 1994. p. 197-221.

BUENO, Edna; SOARES, Lucília; NINFA, Parreiras. Navegar pelas letras: as literaturas de língua Portuguesa. Rio de Janeiro: Civilização Brasileira, 2012.

CABRAL, Amílcar. Libertação nacional e cultura. In: SANCHES, Manuela Ribeiro (Org.). As malhas que os impérios tecem: textos anticoloniais, contextos pós-coloniais. Lisboa: Edições 70, 2011. p. 355-376.

CAMPATO JR., João Adalberto. A poesia da Guiné-Bissau: história e crítica. São Paulo: Arte \& Ciência, 2012.

- Manual de Literaturas de Língua Portuguesa: Portugal, Brasil, África Lusófona e TimorLeste. Curitiba/Rio de Janeiro: CRV/ OPLOP, 2016.

CANDÉ MONTEIRO, Artemisa. Guiné-Bissau: da luta armada à construção do estado nacional: conexões entre o discurso de unidade nacional e diversidade étnica (1959-1994). Tese (Doutorado) - Faculdade de Filosofia e Ciências Humanas, UFBA, Salvador, 2013.

CÂNDIDO, Antônio. O estudo analítico do poema. São Paulo: Humanitas, 1996.

CHARTIER, Roger. A história ou a leitura do tempo. Belo Horizonte: Autêntica, 2009.

COSTA, Saliatu da. Bendita loucura. Bissau: Editora Escolar, 2008.

. Entre a Roseira e a Pólvora, o Capim. Rio de Mouro, Portugal: "Epikart" - Mr. Print, 2011.

COUTO, Hildo H.; EMBALÓ, F. Literatura, língua e cultura na Guiné-Bissau: um país da CPLP. Papia. Revista Brasileira de Estudos Crioulos e Similares, Brasília, v. 20, 2010. Disponível em: $<$ http://revistas.fflch.usp.br/papia/article/view/ 1702/1513 >. Acesso em: 10 ago. 2018.

DUSSEL, Enrique D. Filosofia da Libertação na América Latina. 2. ed. Trad. Luiz João Gaio. São Paulo: Loyola/UNIMEP, 1977. 
EMBALÓ, Filomena. Breve resenha sobre a literatura da Guiné-Bissau. Disponível em: < http:// www. didinho.org/Arquivo/resenhaliteratura. html>. Acesso em: 10 ago. 2018.

FERREIRA, Manuel. Literaturas africanas de expressão portuguesa I. Lisboa: ICALP, 1977.

GOMES, Aldónio; CAVACAS, Fernanda. A literatura na Guiné-Bissau. Lisboa: ME, 1997.

HALL, Stuart. Da diáspora: identidades e mediações culturais. Organização Liv Sovik; Tradução Adelaine La Guardia Resende et al. Belo Horizonte: Editora UFMG, 2003.

HAMILTON, Russell. Literatura africana Literatura necessária II-Moçambique, Cabo Verde, GuinéBissau, São Tomé e Príncipe. Lisboa: INALD, 1983.

Introdução. In: SEPÚLVEDA, Maria do Carmo; SALGADO, Maria Teresa (Org.). África e Brasil: letras em laço. São Bernardo do Campo: Yendis, 2006. p. ix-xxxii.

HERNANDEZ, Leila M. G. L. A África na sala de aula: visita à história contemporânea. 2. ed. rev. São Paulo: Selo Negro, 2008.

LARANJEIRA, Pires. Literaturas africanas de expressão portuguesa. Lisboa: UA, 1995.

LEITE, Ana Mafalda. Oralidades \& Escritas PósColoniais: Estudos Sobre Literaturas Africanas. Rio de Janeiro: EdUERJ, 2012.

LOPES, Carlos. A Pirâmide Invertida - historiografia africana feita por africanos. In: Actas do Colóquio Construção e Ensino da História da África. Lisboa: Linopazas, 1995. p. 21-29.

M'BOKOLO, Elikia. África negra: história e civilizações: tomo 1: até o século XVIII. Salvador: Ed. da Universidade Federal da Bahia, 2009.

MOISÉS, Massaud. A análise literária. São Paulo: CULTRIX, 2007.

NKRUMAH, Kwame. A luta de classes em África. 2. ed. Lisboa: Livraria Sá da Costa, 1977.

SARTRE, Jean-Paul. Que é a literatura? 3. ed. São Paulo: Ática, 2004.

SECCO, Carmen L. T. Travessia e rotas das literaturas africanas de língua portuguesa (das profecias libertárias as distopias contemporâneas). Légua \& meia: Revista de literatura e diversidade cultural, Feira de Santana, BA, n.1, p.91-113, 2002. Disponível em: <http://www2.uefs.br/ leguaemeia/1/1_091_travessia.pdf >. Acesso em: 10 out. 2018.

SEMEDO, Odete Costa. No fundo do canto. Belo Horizonte: Nandyala, 2008.

Entre o ser e o amar. Bissau: Instituto $\overline{\text { Nacional }}$ de Estudos e Pesquisas, 1996.

SILVA, M. G.; MELO, L. C. A. Política, Literatura e a Questãopós-colonial. In: CAMPATO JR., João Adalberto. Manual de Literaturas de Língua Portuguesa: Portugal, Brasil, África Lusófona e Timor-Leste. Curitiba; Rio de Janeiro: CRV; OPLOP, 2016. p. 393-398.

SOARES, Francisco. Literatura e política: três abordagens. Africana Studia: Revista Internacional de Estudos Africanos. Porto, p. 99-110, 2001. Disponível em: <http://www.africanos.eu/ceaup/ uploads/AS04_099.pdf>.Acesso em: 15 out. 2018.

SPIVAC, Gayatri. Pode o subalterno falar? Belo Horizonte: Editora da UFMG, 2010.

TAYLOR, Charles. Multiculturalismo. Lisboa: Instituto Piaget, 1994.

TODOROV, Tzvetan. A conquista da América: a questão do outro. São Paulo. São Paulo: Martins Fontes, 2011.

Recebido: 25 de outubro de 2018

Aceito: 29 de novembro de 2018

\section{LUÍS CARLOS ALVES DE MELO}

Aluno de Doutorado do Programa de Pós-graduação em Letras da Universidade do Estado do Rio de Janeiro (UERJ), Mestre em Letras (Literatura Portuguesa) pela Universidade do Estado do Rio de Janeiro (UERJ). Coordenador Adjunto do Observatório dos Países de Língua Oficial Portuguesa (OPLOP). Bacharel em Relações Internacionais pela Universidade Federal Rural do Rio de Janeiro (UFRRJ). Graduado em Letras (Português/Inglês) pela Faculdade da Alta Paulista - FAP. Bolsista da Coordenação de Aperfeiçoamento de Pessoal de Nível Superior (CAPES).O presente trabalho foi realizado com apoio da Coordenação de Aperfeiçoamento de Pessoal de Nível Superior - Brasil (CAPES) - Código de Financiamento 001. (D) http://orcid.org/0000-0001-6984-6440

<luiiscam@outlook.com> 